\title{
Calibration and validation of a generic multisensor algorithm for mapping of turbidity in coastal waters
}

\author{
B. Nechad, K.G. Ruddick, G. Neukermans \\ Management Unit of the North Sea Mathematical Models (MUMM), Royal Belgian Institute for \\ Natural Sciences (RBINS), Gulledelle 100, 1200 Brussels, Belgium
}

\begin{abstract}
Turbidity, as defined in the standard ISO7027, is a parameter that is routinely measured in many national and regional water quality monitoring programmes. The definition of turbidity according to ISO and as related to satellite data products is discussed. While satellite data products are beginning to become available for the closely related parameter, Total Suspended Matter (TSM), the direct estimation of turbidity as a satellite data product has not yet been addressed. In situ measurements of TSM and of turbidity, obtained in the Southern North Sea (SNS), show high correlation (correlation coefficient of 98.6\%). A generic multisensor algorithm for TSM as function of reflectance has been previously developed. The methodology is extended here to the estimation of turbidity from water-leaving reflectance. A set of 49 seaborne measurements of reflectance in the spectral range $600-850 \mathrm{~nm}$ and turbidity in the SNS are used to calibrate the algorithm. The algorithm is also calibrated for the specific bands of MERIS. Validation of these models is carried out using an independent set of seaborne measurements of turbidity and reflectance and shows low relative errors in turbidity retrieval at $681 \mathrm{~nm}$ (less than $35 \%$ ). This wavelength is recommended, provided no significant fluorescence affects this range.
\end{abstract}

Keywords: Turbidity, Generic optical algorithm, Remote Sensing Application, Marine Strategy Directive

\section{INTRODUCTION}

The objective of this paper is to calibrate an algorithm for mapping of turbidity by optical remote sensing. The motivation for remote sensing of turbidity, rather than related parameters such as Total Suspended Matter concentration (TSM) or beam attenuation coefficient, $c$, comes from the European Union's Marine Strategy Framework Directive ${ }^{1}$. This directive will largely set the monitoring requirements in the EU over the next decade and lists turbidity (Annex III, Table 1) as a parameter which must be considered for the definition and assessment of "good environmental status". Apart from this regulatory requirement, turbidity is also often used as a simply-measured proxy for TSM, where the main interest is in sediment transport, or for more environmentally-relevant optical parameters such as diffuse attenuation coefficient for downwelling irradiance, $K_{d}$. The relationships between TSM, turbidity and other optical parameters are discussed in detail in a number of reviews, e.g. ${ }^{2,3}$.

\subsection{Definition}

Before describing the theoretical basis and calibration of an algorithm to retrieve turbidity it is worth clarifying the definition of this term. Because of strong correlation between turbidity and other parameters such as TSM concentration, reflectance, backscatter, transparency and beam and diffuse attenuation there is considerable confusion regarding usage of the term "turbidity". The lay definition of turbid as "cloudy, opaque, or thick with suspended matter" [Concise Oxford Dictionary of English Etymology, 1996] could refer to high scattering, high beam attenuation or high TSM. For example, for scientists describing "turbid water" atmospheric correction algorithms, the property of interest is really (near infrared) reflectance rather than turbidity. In the present study the definition of turbidity is based on the International Standard Organisation ISO $7027^{4}$ quantitative measurement of "diffuse radiation". In more precise optical terms, this is a measurement at $860 \mathrm{~nm}$ of the ratio of $90^{\circ}$-scattered light to forward-transmitted light as compared to the same ratio for a suspension of Formazin $\left(\mathrm{C}_{2} \mathrm{H}_{4} \mathrm{~N}_{2}\right)$. Using this definition turbidity is measured in Formazin Nephelometric Units (FNU),

Remote Sensing of the Ocean, Sea Ice, and Large Water Regions 2009,

edited by Charles R. Bostater Jr., Stelios P. Mertikas, Xavier Neyt, Miguel Velez-Reyes,

Proc. of SPIE Vol. $7473,74730 \mathrm{H} \cdot$ @ 2009 SPIE · CCC code: 0277-786X/09/\$18 - doi: 10.1117/12.830700

Proc. of SPIE Vol. $747374730 \mathrm{H}-1$ 
with $1 \mathrm{FNU}$ corresponding to the $90^{\circ}$ scattering produced by dissolving $5 \mathrm{~g}$ of hexamethylenetetramine $\left(\mathrm{C}_{6} \mathrm{H}_{12} \mathrm{~N}_{4}\right)$ and $0.5 \mathrm{~g}$ of hydrazine sulfate $\left(\mathrm{N}_{2} \mathrm{H}_{6} \mathrm{SO}_{4}\right)$ in $4000 * 100 \mathrm{ml}$ of particle-free water. The use of monochromatic near infrared light in this definition is critical in reducing the impact of particulate and coloured dissolved organic matter absorption. Previous definitions of turbidity such as the EPA method ${ }^{5}$, using a tungsten light source with color temperature between $2200-3000 \mathrm{~K}$ and detector and filter system with spectral peak response "between $400 \mathrm{~nm}$ and $600 \mathrm{~nm}$ ", are particularly poorly defined. Not surprisingly different instruments designed according to the vague EPA specification may give very different measurements for the same sample. This has led to a general rejection by the aquatic optics community of turbidity as a precisely measurable parameter. Although still defined as a parameter relative to Formazin rather than as an absolute inherent optical property, the ISO definition of turbidity does provide a reasonable basis for intercomparability of measurements. Intercomparison of five portable nephelometric turbidimeters is described by ${ }^{6} .{ }^{7}$ compared a range of optical instruments, based variously on transmission, side scattering (corresponding to the ISO turbidity method) and backscattering measurements. High correlation was found between TSM and all these optical parameters, with best correlation for backscatter measurements.

The in situ measurement of turbidity and associated issues of instrumentation (acceptance angles, straylight, pathlength, etc.), sample preparation (cleaning/oiling of cells, mixing, debubbling, etc.) and standards for calibration are dealt with in detail in ${ }^{8,3}$. Suffice to say here that, with a well-designed instrument with sufficiently small acceptance angle and operating in the single-scattering regime, the turbidity measured by an ISO nephelometer measuring transmitted and $90^{\circ}$ scattered light will be equal to the ratio of the volume scattering function of the sample at $90^{\circ}, \beta_{90^{\circ}}$ as compared to the volume scattering function at $90^{\circ}$ for 1 unit of Formazin, $\beta_{90^{\circ}}^{F}$. To our knowledge $\beta_{90^{\circ}}^{F}$ has not been directly measured, although ${ }^{9}$ reports measurements at a $45^{\circ}$ scattering angle, $\beta_{45^{\circ}}^{F}$.

\subsection{Remote sensing algorithm}

Unlike TSM, turbidity is not a standard product for ocean colour sensors such as MERIS. Of course, because of the strong correlation between TSM and turbidity many of the considerations of TSM algorithm design ${ }^{10}$ apply equally to turbidity algorithms with the simplification that turbidity, as an optical property, is not affected by variation of the mass density of particulate material. Studies specifically on remote sensing of turbidity are less numerous. ${ }^{11}$ tested various algorithms for turbidity estimation against in situ data for 3 tropical coastal water sites and suggested a global algorithm based on remote sensing reflectance at $681 \mathrm{~nm}$, Rrs681, for turbidities greater than $1 \mathrm{FTU}$ or an algorithm based on Rrs620.Rrs681/Rrs412 for the least turbid waters. ${ }^{12}$ used LANDSAT band $3(630-690 \mathrm{~nm})$ to map turbidity in Guadalquivir River. ${ }^{13}$ used LISS-I band $3(620-680 \mathrm{~nm})$ to map turbidity in the Tawa reservoir region. ${ }^{14}$ used SPOTHRV2 band (610-680nm) to map turbidity in the Tuttel Creek Reservoir.

In the present study a bio-optical model is developed relating turbidity, $\mathrm{T}$, to water-leaving reflectance, $\rho_{w}$, defined as $\pi L_{w} / E_{d}^{0+}$ where $L_{w}$ is the water-leaving radiance (after removal of air-water interface reflection) and $E_{d}^{0+}$ is the downwelling irradiance. The calibration of the model is carried out using in situ measurements of $\mathrm{T}$ and $\rho_{w}$ (described in section 3) and non-linear regression analysis.

\section{THEORY}

The theoretical basis for the algorithm developed here is based on the TSM algorithm described in ${ }^{15}$ and ${ }^{10}$. The present study merely adapts that algorithm by replacing the backscatter/TSM relationship with a backscatter/turbidity relationship. In this section the theory is briefly summarised. For full details of the theoretical basis including estimation of uncertainties introduced by the various model assumptions, the reader is referred to ${ }^{10}$. 
Water-leaving reflectance is related to the inherent optical properties, absorption and backscatter coefficient, $a$ and $b_{b}$ by the first order version of the model of ${ }^{16}$ :

$$
\rho_{w}=\pi R \frac{f^{\prime}}{Q}\left(\frac{b_{b}}{a+b_{b}}\right)=\gamma\left(\frac{b_{b}}{a+b_{b}}\right)
$$

where $\mathfrak{R}$ represents reflection and refraction effects at the sea surface ${ }^{17}, f^{\prime}$ is a varying dimensionless factor ${ }^{18}$ and $Q$ is the ratio of subsurface upwelling irradiance to the subsurface upwelling radiance in the viewing direction. Taking typical values of $\mathfrak{R}=0.529{ }^{17}$ and $f^{\prime} / Q=0.13$ for sediment-dominated waters ${ }^{19}$ and grouping these factors gives $\gamma=\pi \Re f^{\prime} / Q \approx 0.216$.

\subsection{The Inherent Optical Property (IOP) model}

The absorption and backscattering are expressed in terms of particulate ( $p$ subscript) and non particulate $(n p)$ contributions as follows:

$$
a=a_{p}+a_{n p}, \quad b_{b}=b_{b p}+b_{b n p} \quad\left[\mathrm{~m}^{-1}\right]
$$

The non-particulate backscatter is assumed negligible compared to particulate backscatter in turbid waters, $b_{b n p}=0$. We define the turbidity-specific particulate absorption and turbidity-specific backscattering as follows:

$$
a_{p T}^{*}=\frac{a_{p}}{T}, b_{b p T}^{*}=\frac{b_{b p}}{T} \quad\left[\mathrm{~m}^{-1} \mathrm{FNU}^{-1}\right]
$$

Using (1), (2) and (3) the turbidity can be expressed in terms of the water-leaving reflectance as follows:

$$
T=\frac{A_{T} \rho_{w}}{1-\rho_{w} / C} \quad\left[\mathrm{FNU}^{-1}\right]
$$

with

$$
C=\gamma \frac{b_{b p T}^{*}}{a_{p T}^{*}+b_{b p T}^{*}}[\text { dimensionless }], A_{T}=\frac{a_{n p}}{\gamma b_{b p T}^{*}} \quad\left[\mathrm{FNU}^{-1}\right]
$$

The two calibration parameters $A_{T}$ and $C$ have different importance: any errors in calibration of $C$ have negligible impact in the linear regime (in the red and near infrared spectral ranges: $\rho_{w}<<C \Rightarrow T \approx A_{T} \rho_{w}$ ) where the algorithm will mainly be used. For this reason, $C$ is calibrated using "standard" IOP data as described and tabulated in ${ }^{10}$. The $C$ factor used here for the turbidity algorithm is strictly the same as that used for the TSM algorithm in the referred paper. The A factors used in these algorithms for turbidity, $A_{T}$, and TSM, $A_{T S M}$, differ by the ratio of TSM:turbidity since $A_{T S M}=\frac{a_{n p}}{\gamma b_{b p}^{*}}$, where $b_{b p}^{*}=\frac{b_{b p}}{T S M}$.

\section{METHOD}

The algorithm (4) has a single free calibration parameter, $A_{T}$. To account for measurement and model errors, this equation is modified by adding a second coefficient $B_{T}$ :

$$
T=\frac{A_{T} \rho_{w}}{1-\rho_{w} / C}+B_{T}
$$


Non linear least-square regression analysis is used to find the optimal parameters $A_{T}$ and $B_{T}$ in equation (6), that give the best fit to turbidity and $\rho_{w}$ measurements.

\subsection{Data}

Surface water is sampled with a bucket from the starboard side of the research vessel Belgica. Simultaneously, abovewater marine reflectance is recorded from the prow of the vessel with a set of TriOS Ramses radiometers. From a total of 242 available turbidity and reflectance measurements, 49 measurements were selected with small deviation $(<25 \%)$ from the time-averaged mean reflectance at $780 \mathrm{~nm}$ (for details see ${ }^{20}$ ). A random selection has been performed to establish separate datasets dedicated to the calibration (26 measurements, Figure 1c) and to the validation (23, Figure 1d) of the turbidity algorithm. Measurements have been taken in the Southern North Sea (SNS) area, under a range of meteorological and oceanographic conditions summarized in Table 1. The SNS region is relatively shallow and subject to strong vertical mixing, due to tides and currents, which induces sediment resuspension.

Table 1. Summary of measurements, sea and sky conditions

\begin{tabular}{|lll|}
\hline \multicolumn{1}{|c}{$\begin{array}{c}\text { min-max (mean) } \\
\text { Number }\end{array}$} & \multicolumn{1}{c|}{$\begin{array}{c}\text { Calibration } \\
\text { 26 }\end{array}$} & \multicolumn{1}{c|}{$\begin{array}{c}\text { Validation } \\
\text { 23 }\end{array}$} \\
\hline Water depth $(\mathrm{m})$ & $0.3-52.0(18.3)$ & $5.4-56.0(21.4)$ \\
Sun zenith angle $\left({ }^{\circ}\right)$ & $29.3-83.3(51.0)$ & $28.5-82.0(55.2)$ \\
Wind speed $(\mathrm{m} / \mathrm{s})$ & $0.3-14.1(6.0)$ & $1.9-18.2(6.9)$ \\
Wave height $(\mathrm{m})$ & $0.0-1.0(0.3)$ & $0.1-1.5(0.4)$ \\
Cloud cover $(/ 8)$ & $0-8(4)$ & $0-8(5)$ \\
Secchi depth $(\mathrm{m})$ & $0.3-5.8(1.6)$ & $0.3-6.5(2.1)$ \\
TSM (mg/l) & $0.22-66.48(17.49)$ & $0.55-68.22(15.68)$ \\
Chlorophyll-a $(\mu \mathrm{g} / \mathrm{l})$ & $0.45-63.56(10.73)$ & $0.61-124.09(16.08)$ \\
Turbidity $(\mathrm{FNU})$ & $0.65-83.63(17.98)$ & $0.59-82.5(16.55)$ \\
\hline
\end{tabular}

Turbidity is measured with a portable HACH 2100P ISO turbidimeter. The instrument records turbidity between 0 and $1000 \mathrm{FNU}$, with a resolution of $0.01 \mathrm{FNU}$. The average response over 10 measurements at 1.2 second intervals is taken (signal averaging) and the auto-range function is used. The turbidimeter was calibrated in April 2007 using a set of STABLCAL Stabilized Formazin Turbidity Standards with turbidities of $<0.1,20,100$ and 800 FNU, prepared according to the instructions of the manufacturer.

At the start of each sea campaign, covering 4 to 5 days, turbidities of the STABLCAL Standards are recorded to ensure instrument stability. For measurement of turbidity, a $15 \mathrm{ml}$ glass sample cell is filled with properly mixed sampled water after rinsing the cell once with the sample. At the beginning of each day at sea, several drops of silicon oil are put on a soft microfiber lint-free cloth. The exterior sample cells are (i) rinsed with milliQ water, (ii) dried with paper tissue, (iii) swiped with the oiled cloth, and (iv) with a dry cloth. Prior to turbidity measurement, the sample cell is visually inspected for dust particles or air bubbles. Three replicate turbidity measurements are recorded for each water sample, gently tumbling the sample cell three times between each turbidity measurement. 
Turbidity is recorded before and after filtration for suspended matter and chlorophyll $a$ concentration, to ensure good mixing, quality control of suspended matter concentration and to detect possible handling errors. Comparison of turbidity data with the in situ TSM data allows a quality check of the TSM data (and particulate scattering or backscattering data), highlighting suspect or extreme data (Figure 1a) ${ }^{21}$. Measurement of turbidity before filtration allows filtration volume to be optimally set, ensuring that enough matter is collected for accurate measurement but not so much that the filter clogs. Comparison of the turbidity data before and after filtration provides a quality check on mixing of the water sample during the subsampling and filtration operations. The distribution of turbidity measurements used in this study is quasilognormal (Figure 1b).
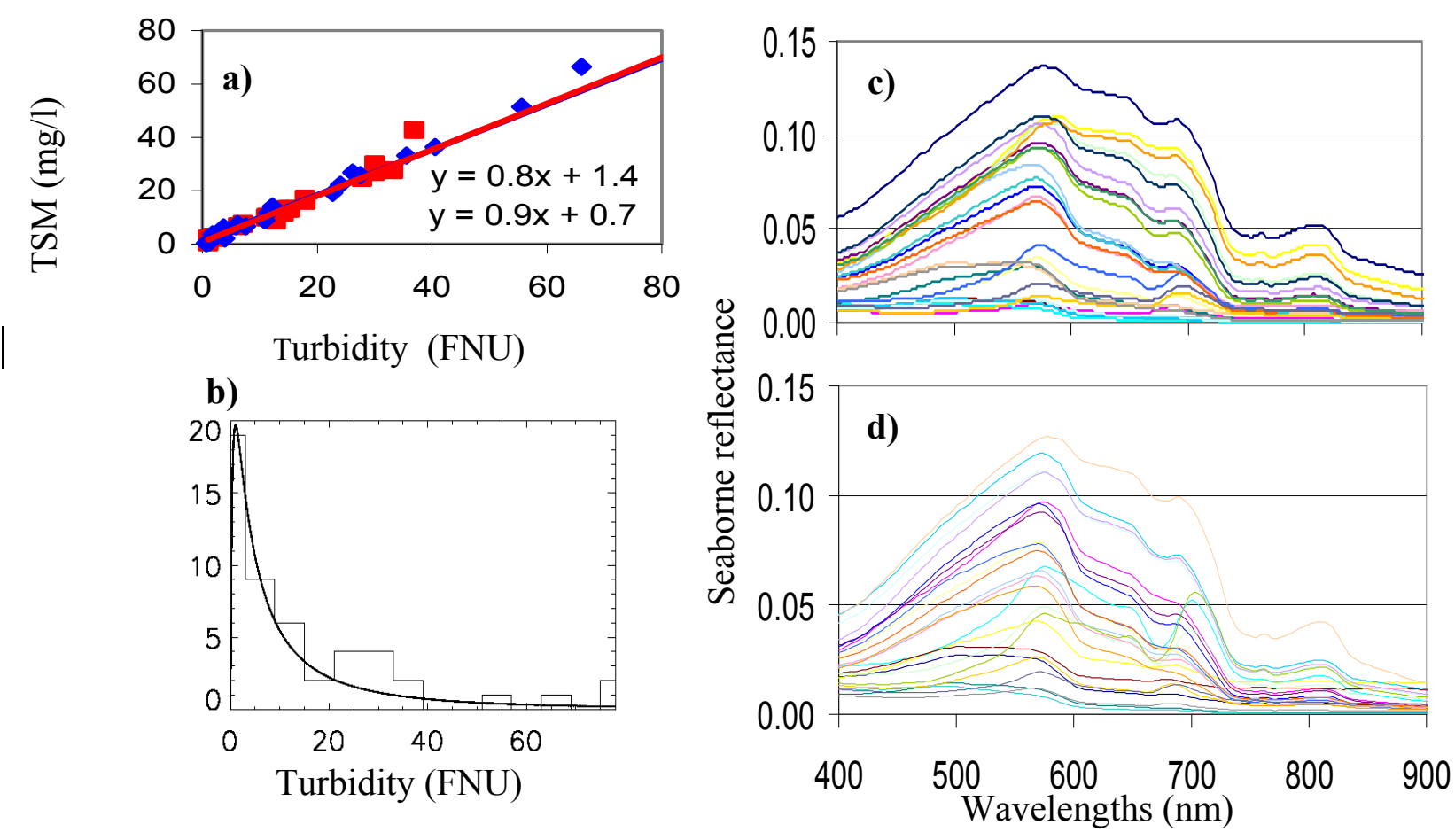

Figure 1: The 49 seaborne measurements of TSM, turbidity and reflectance simultaneously collected in the Southern North Sea from April 2007 to September 2008: a) TSM versus turbidity measurements from the calibration dataset (blue) and the validation data collection (red), b) the distribution of 49 turbidity data, c) reflectance measurements for calibration and d) for validation.

\subsection{Calibration}

A sensor-specific calibration of the algorithm is carried out using 26 seaborne measurements of turbidity denoted by $T_{i}$ and band-weighted reflectances $\rho_{w}^{i, k}, i=1 \ldots N$, and $k=1 \ldots K$ where $K$ is the number of bands for a given sensor $(k$ is dropped hereafter for brevity), model estimates are denoted by $T_{i}^{m}$ and the mean value of turbidity measurements by $\bar{T}$. The residual or error sum of squares, $S S E$, and the coefficient of multiple determination, $R^{2}$, are defined respectively by :

$$
S S E=\sum_{i=1}^{N}\left(T_{i}-T_{i}^{m}\right)^{2} \text { and } R^{2}=1-S S E / \sum_{i=1}^{N}\left(T_{i}-\bar{T}\right)^{2}
$$


$R^{2}$ varies between 0 and 1 and indicates the fraction of variance in the observations set $\left(T_{i}\right)$ that is explained by the regression model. If $R^{2}=1$ then the curve fits all data points. The coefficient $A_{T}$ that minimizes $S S E$, corresponding to the highest $R^{2}$, is selected for our algorithm calibration. However, since the variance of $T_{i}$ increases with increasing $\rho_{w}^{i}$, and have a quasi-lognormal distribution (see Figure 1), the log-transformed turbidity data are more likely to stabilize this variance ${ }^{22}$.

Hence, $S S E$ and $R^{2}$ defined in (7) are rewritten to express the log-transformation:

$$
\left\{\begin{array}{l}
S S E_{\log }=\sum_{i=1}^{N}\left[\log \left(T_{i}\right)-\log \left(T_{i}^{m}\right)\right]^{2} \\
R^{2}=1-\frac{S S E_{\log }}{\sum_{i=1}^{N}\left[\log \left(T_{i}\right)-\sum_{j=1}^{N} \log \left(T_{j}\right) / N\right]^{2}}
\end{array}\right.
$$

Following the same method, the hyperspectral calibration is performed, using the red to near infrared spectral range of the seaborne reflectances, $\rho_{w}^{i}$, separately for each wavelength from $600 \mathrm{~nm}$ to $885 \mathrm{~nm}$, with a step of $2.5 \mathrm{~nm}$.

\section{RESULTS}

Figure 2 shows the curves derived from the regression superimposed on the calibration dataset for reflectances taken at MERIS bands centered around wavelengths $620 \mathrm{~nm}, 665 \mathrm{~nm}, 681 \mathrm{~nm}$ and $708 \mathrm{~nm}$. The best curve fits are noted at $681 \mathrm{~nm}$ and $665 \mathrm{~nm}$ respectively with $R^{2}=95.5 \%$ and $R^{2}=94.9 \%$. This is in good agreement with which empirically set an algorithm for turbidity in terms of remote sensing reflectance, using in situ measurements from various tropical coastal waters. The value $A_{T}(620 \mathrm{~nm})=174 \mathrm{FNU}$ is similar magnitudes to $A_{T}^{o}(620 \mathrm{~nm})=159 \mathrm{FNU}$ that could be derived from ${ }^{11}$ (using Figure 5).

At lower wavelength $(620 \mathrm{~nm})$, the curve is slightly less linear due to the proximity to the "saturation" asymptote as $\rho_{w} \rightarrow C$ in (4). However, the performance of the curve fitting seems similar over the 4 bands including wavelength $708 \mathrm{~nm}$ with $R^{2}=94.2 \%$. Note the quasi-perfect curve fit to measurements at higher turbidity values (T>20FNU). On the contrary, higher scattering of points around the curve is noticed in the lower ranges, which may be explained by the lack of sufficient precision in reflectance measurements in these waters.

At wavelengths longer than $708 \mathrm{~nm}$ the regression coefficient $R^{2}$ falls under $87.6 \%$ due to the higher uncertainties in the reflectance measurements in this spectral range.

The hyperspectral calibration provided the full spectrum of $A_{T}$ and $B_{T}$ (Table 2). $A_{T}$, normalised by $A_{T}(780 \mathrm{~nm})$ is shown in Figure 3. This spectrum retrieved by regression analysis using seaborne measurements of turbidity and reflectance has an identical shape to the pure water absorption spectrum, $a_{w}$. Figure 3 also shows the spectrum of the $A_{T S M}$ parameter of ${ }^{10}$, calibrated for TSM algorithms using a different seaborne measurement dataset (2002-2006) of reflectance and TSM, and a similar relationship to equation (4) (equation (12) in the cited paper). 


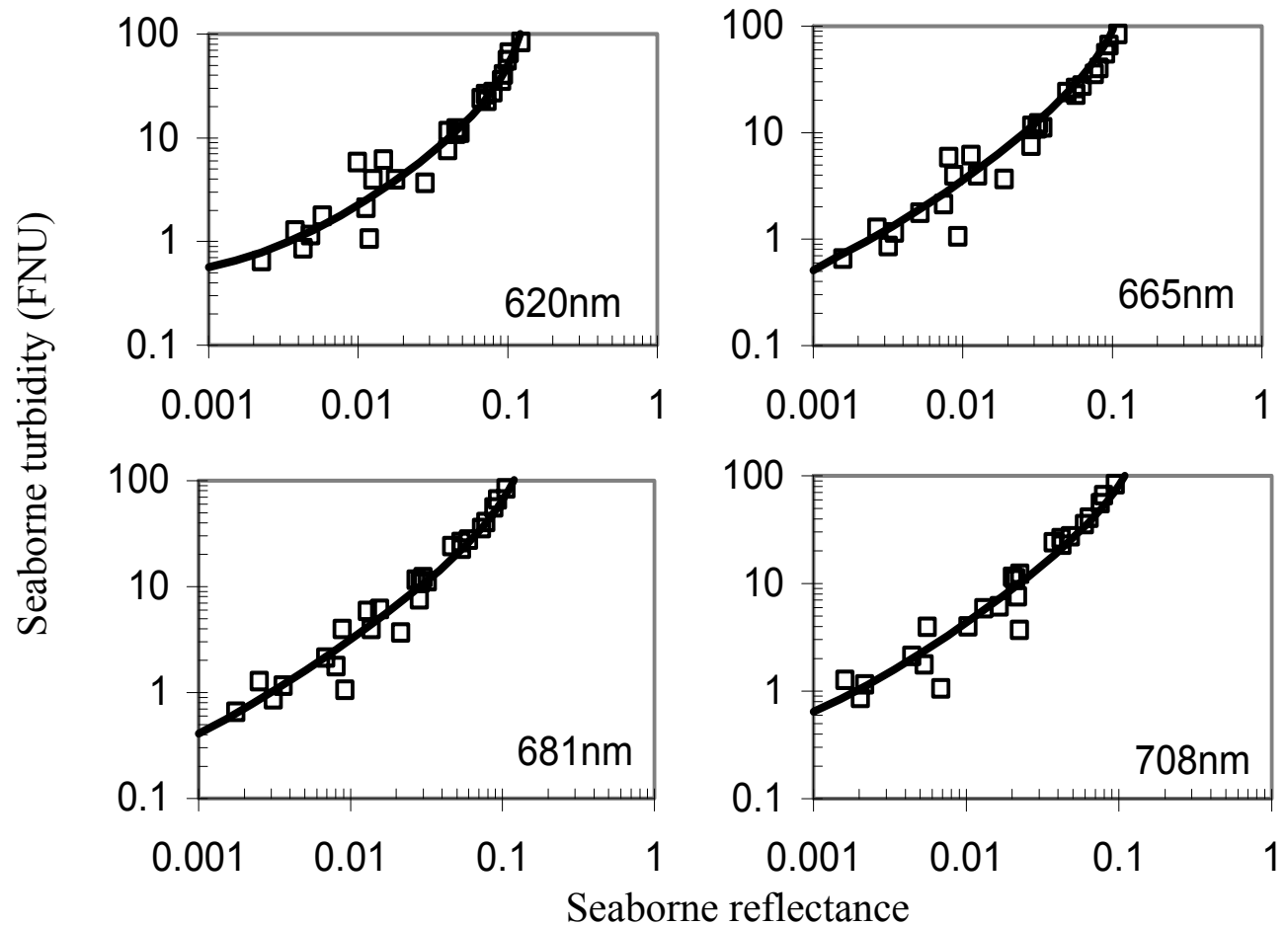

Figure 2: The best fitting curves for equation (6) derived by regression analysis applied to 26 seaborne turbidity and reflectance measurements taken at MERIS bands (here only wavelengths 620, 665, 681 and 708nm are shown), superimposed on the scatterplot of turbidity versus reflectance (squares).

The bio-optical model parameterisation neglects time and space variability of the particulate specific absorption and specific backscatter (through the determination of the $C$ factor), but made no assumption on the spectral shapes of $a_{n p}$ and $b_{b p}^{*}$. The resulting parameters calibrated with turbidity and reflectances taken in the SNS area indicate that: a) in these waters, CDOM has limited contribution to the total absorption in the red to near infrared spectral ranges, which agrees with direct measurements by ${ }^{23}$, and so $\mathrm{b}$ ) the regression analysis of both algorithms (using separate data sets) have reproduced realistic spectra of $A_{T S M}=a_{n p} / b_{b p}^{*}$ and $A_{T}=a_{n p} / b_{b p T}^{*}$ (with similar shapes) and c) the $b_{b p}^{*}$ and $b_{b p T}^{*}$ are spectrally quite flat.

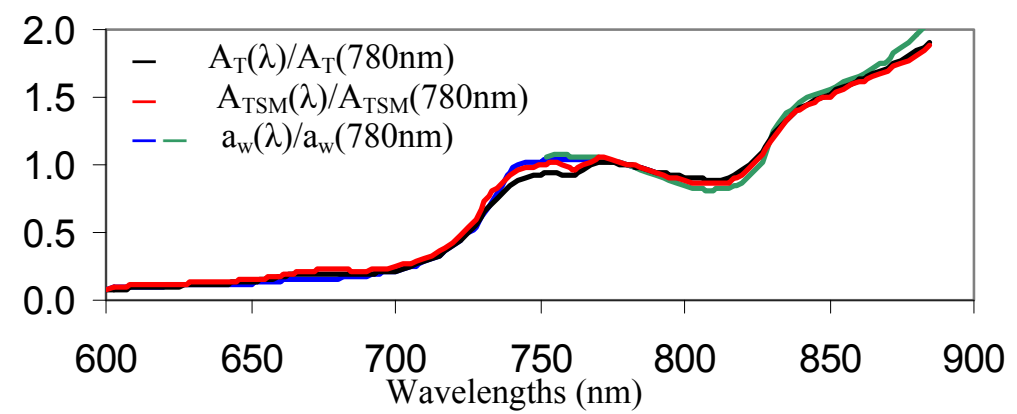

Figure 3: The $A_{T}$ calibration coefficient for wavelengths ranging from $600 \mathrm{~nm}$ to $885 \mathrm{~nm}$ and normalized at $780 \mathrm{~nm}$ (black line) superimposed on the $A_{T S M}$ coefficient from ${ }^{10}$ (red) and with the pure water absorption normalised at $780 \mathrm{~nm}$ using data from ${ }^{24}$ for $\lambda>751 \mathrm{~nm}$ (green) and data from ${ }^{25}$ for $500 \mathrm{~nm}<\lambda<800 \mathrm{~nm}$ (blue). 
Table 2: $A_{T}$ (FNU), $B_{T}$ (FNU) and $R^{2}$ coefficients for a generic narrow band turbidity algorithm for wavelengths ranging from $600 \mathrm{~nm}$ to $885 \mathrm{~nm}$.

\begin{tabular}{|c|c|c|c|c|c|c|c|c|c|c|c|}
\hline$\lambda(n m)$ & $A_{T}$ & $B_{T}$ & $R^{2} \%$ & $\lambda(\mathrm{nm})$ & $A_{T}$ & $B_{T}$ & $R^{2} \%$ & $\lambda(n m)$ & $A_{T}$ & $B_{T}$ & $R^{2} \%$ \\
\hline 600.0 & 127.31 & 0.45 & 92.9 & 700.0 & 316.38 & 0.26 & 94.7 & 800.0 & 1165.15 & 0.14 & 89.0 \\
\hline 602.5 & 137.28 & 0.43 & 93.4 & 702.5 & 333.50 & 0.26 & 94.6 & 802.5 & 1153.92 & 0.15 & 89.2 \\
\hline 605.0 & 146.29 & 0.41 & 93.7 & 705.0 & 354.20 & 0.26 & 94.5 & 805.0 & 1148.32 & 0.15 & 89.3 \\
\hline 607.5 & 153.40 & 0.40 & 93.9 & 707.5 & 377.65 & 0.26 & 94.3 & 807.5 & 1137.28 & 0.16 & 89.0 \\
\hline 610.0 & 158.26 & 0.40 & 94.0 & 710.0 & 403.91 & 0.26 & 94.0 & 810.0 & 1136.51 & 0.16 & 89.0 \\
\hline 612.5 & 162.45 & 0.40 & 94.1 & 712.5 & 434.38 & 0.25 & 93.8 & 812.5 & 1138.86 & 0.17 & 89.0 \\
\hline 615.0 & 166.70 & 0.39 & 94.1 & 715.0 & 465.96 & 0.24 & 93.5 & 815.0 & 1149.81 & 0.17 & 88.9 \\
\hline 617.5 & 170.74 & 0.39 & 94.1 & 717.5 & 503.79 & 0.23 & 93.1 & 817.5 & 1176.71 & 0.18 & 89.1 \\
\hline 620.0 & 174.41 & 0.39 & 94.1 & 720.0 & 551.04 & 0.22 & 92.6 & 820.0 & 1218.00 & 0.16 & 88.7 \\
\hline 622.5 & 177.53 & 0.39 & 94.1 & 722.5 & 608.75 & 0.21 & 92.2 & 822.5 & 1274.55 & 0.15 & 88.3 \\
\hline 625.0 & 180.51 & 0.39 & 94.1 & 725.0 & 679.38 & 0.18 & 91.7 & 825.0 & 1346.28 & 0.14 & 87.9 \\
\hline 627.5 & 183.47 & 0.39 & 94.1 & 727.5 & 758.70 & 0.16 & 91.1 & 827.5 & 1435.92 & 0.11 & 87.4 \\
\hline 630.0 & 186.72 & 0.39 & 94.1 & 730.0 & 849.30 & 0.13 & 90.3 & 830.0 & 1523.25 & 0.09 & 86.4 \\
\hline 632.5 & 190.59 & 0.39 & 94.1 & 732.5 & 944.60 & 0.09 & 89.6 & 832.5 & 1613.09 & 0.07 & 85.6 \\
\hline 635.0 & 194.79 & 0.38 & 94.2 & 735.0 & 1027.32 & 0.06 & 88.8 & 835.0 & 1693.52 & 0.06 & 84.8 \\
\hline 637.5 & 198.41 & 0.38 & 94.2 & 737.5 & 1094.80 & 0.04 & 88.3 & 837.5 & 1760.87 & 0.05 & 84.1 \\
\hline 640.0 & 202.39 & 0.37 & 94.3 & 740.0 & 1149.39 & 0.02 & 87.8 & 840.0 & 1810.59 & 0.02 & 83.4 \\
\hline 642.5 & 204.91 & 0.37 & 94.3 & 742.5 & 1186.51 & 0.01 & 87.4 & 842.5 & 1841.15 & 0.02 & 82.9 \\
\hline 645.0 & 208.41 & 0.36 & 94.4 & 745.0 & 1210.17 & 0.01 & 87.1 & 845.0 & 1873.85 & 0.02 & 82.6 \\
\hline 647.5 & 212.25 & 0.36 & 94.5 & 747.5 & 1232.76 & 0.00 & 86.9 & 847.5 & 1905.40 & 0.01 & 82.2 \\
\hline 650.0 & 217.79 & 0.35 & 94.5 & 750.0 & 1249.27 & 0.00 & 86.7 & 850.0 & 1930.95 & -0.01 & 81.8 \\
\hline 652.5 & 225.40 & 0.34 & 94.5 & 752.5 & 1251.35 & 0.01 & 86.2 & 852.5 & 1963.54 & 0.00 & 81.9 \\
\hline 655.0 & 235.32 & 0.33 & 94.5 & 755.0 & 1254.27 & 0.01 & 86.0 & 855.0 & 1986.58 & 0.00 & 81.5 \\
\hline 657.5 & 247.10 & 0.32 & 94.5 & 757.5 & 1239.63 & 0.02 & 86.4 & 857.5 & 2018.16 & 0.00 & 81.1 \\
\hline 660.0 & 261.11 & 0.29 & 94.6 & 760.0 & 1218.53 & 0.03 & 86.4 & 860.0 & 2059.37 & -0.01 & 80.8 \\
\hline 662.5 & 273.32 & 0.26 & 94.7 & 762.5 & 1219.57 & 0.04 & 86.7 & 862.5 & 2066.84 & 0.00 & 80.1 \\
\hline 665.0 & 282.95 & 0.23 & 94.8 & 765.0 & 1271.65 & 0.04 & 87.5 & 865.0 & 2109.35 & -0.02 & 80.3 \\
\hline 667.5 & 290.68 & 0.19 & 95.1 & 767.5 & 1314.26 & 0.04 & 87.3 & 867.5 & 2137.33 & -0.03 & 80.0 \\
\hline 670.0 & 294.24 & 0.16 & 95.3 & 770.0 & 1342.56 & 0.04 & 87.6 & 870.0 & 2169.30 & -0.03 & 79.9 \\
\hline 672.5 & 295.69 & 0.13 & 95.5 & 772.5 & 1348.92 & 0.04 & 87.6 & 872.5 & 2212.57 & -0.03 & 80.0 \\
\hline 675.0 & 294.47 & 0.12 & 95.6 & 775.0 & 1335.58 & 0.04 & 87.5 & 875.0 & 2243.05 & -0.03 & 79.4 \\
\hline 677.5 & 292.51 & 0.11 & 95.6 & 777.5 & 1318.23 & 0.05 & 87.6 & 877.5 & 2281.62 & -0.03 & 78.7 \\
\hline 680.0 & 290.81 & 0.11 & 95.5 & 780.0 & 1304.10 & 0.05 & 87.6 & 880.0 & 2320.83 & -0.05 & 78.3 \\
\hline 682.5 & 285.64 & 0.12 & 95.4 & 782.5 & 1287.19 & 0.06 & 87.7 & 882.5 & 2357.62 & -0.08 & 77.8 \\
\hline 685.0 & 280.32 & 0.14 & 95.3 & 785.0 & 1270.04 & 0.07 & 87.9 & 885.0 & 2390.57 & -0.07 & 76.8 \\
\hline 687.5 & 277.03 & 0.17 & 95.2 & 787.5 & 1250.32 & 0.09 & 88.1 & & & & \\
\hline 690.0 & 277.29 & 0.19 & 95.1 & 790.0 & 1231.91 & 0.10 & 88.3 & & & & \\
\hline 692.5 & 283.69 & 0.21 & 95.0 & 792.5 & 1212.51 & 0.11 & 88.4 & & & & \\
\hline 695.0 & 292.45 & 0.23 & 94.9 & 795.0 & 1195.20 & 0.12 & 88.6 & & & & \\
\hline 697.5 & 303.09 & 0.25 & 94.8 & 797.5 & 1179.04 & 0.13 & 88.9 & & & & \\
\hline
\end{tabular}

\section{VALIDATION AND APPLICATION}


Turbidity estimates from reflectances at wavelengths $<708 \mathrm{~nm}$ gave relative errors between $30 \%$ and $35 \%$. The regression in the logarithmic space between modeled and measured turbidity shows a quasi 1:1 line (the red lines in Figure 4) and points equally scattered around this line at $620 \mathrm{~nm}$. A better performance of the algorithm is observed at $708 \mathrm{~nm}$, where the highest linear correlation value $\mathrm{r}^{2} \sim 98 \%$ and the lowest root mean squared errors (RMSE $\sim 5 \mathrm{FNU}$ ) were found. On the contrary, the relative error is higher for lower turbidity $<1 \mathrm{FNU}$, which could be due to errors in reflectance measurements.
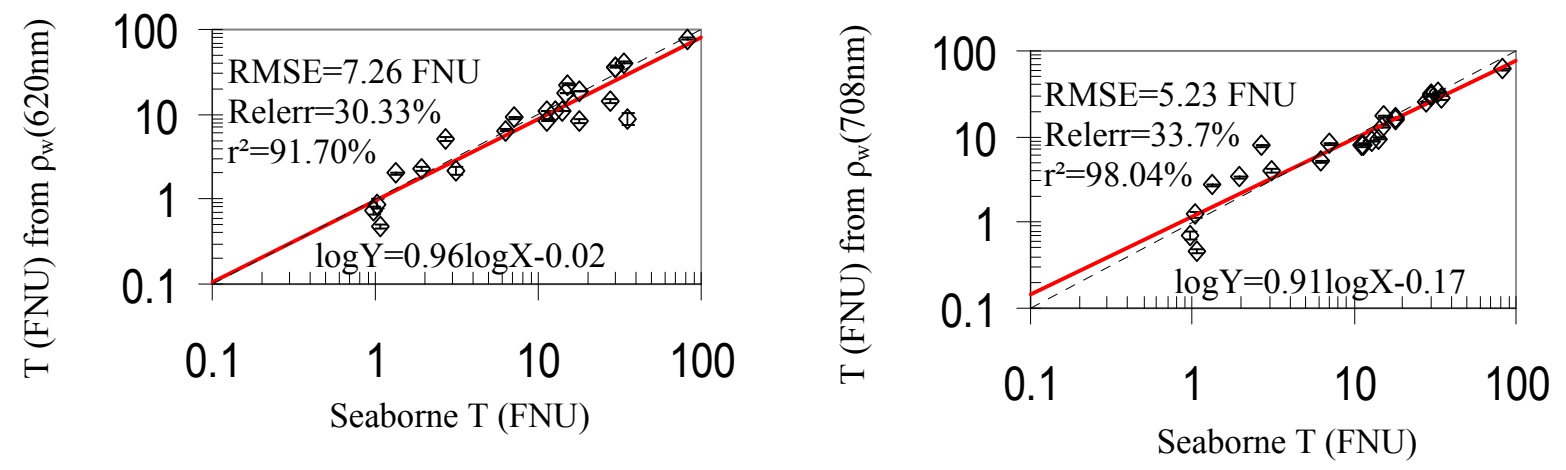

Figure 4: Regression analysis of In situ versus mapped/modeled turbidity from MERIS bands centered around 620nm (left) and 708nm (right). The dashed curve shows the 1:1 line.

The turbidity algorithm was applied to a MODIS image taken on September $8^{\text {th }} 2003$, at 12:00UTC. The water-leaving reflectance was retrieved from the top of atmosphere radiance using the SeaDAS software with the turbid water extension of ${ }^{26}$. Since wavelengths from $681 \mathrm{~nm}$ to $708 \mathrm{~nm}$ are considered optimal for turbidity retrieval, as shown from the calibration analysis and from validation, and to avoid larger errors in the retrieved NIR reflectance, band $678 \mathrm{~nm}$ was chosen as a compromise between longer wavelengths (MODIS band 748nm) and shorter wavelengths (MODIS band $667 \mathrm{~nm})$.

A TSM concentration map was derived from the TSM algorithm by ${ }^{10}$, and using band $667 \mathrm{~nm}$. Not surprisingly, similar patterns in turbidity (FNU) and TSM (mg/l) are observed, as shown in Figure 5.
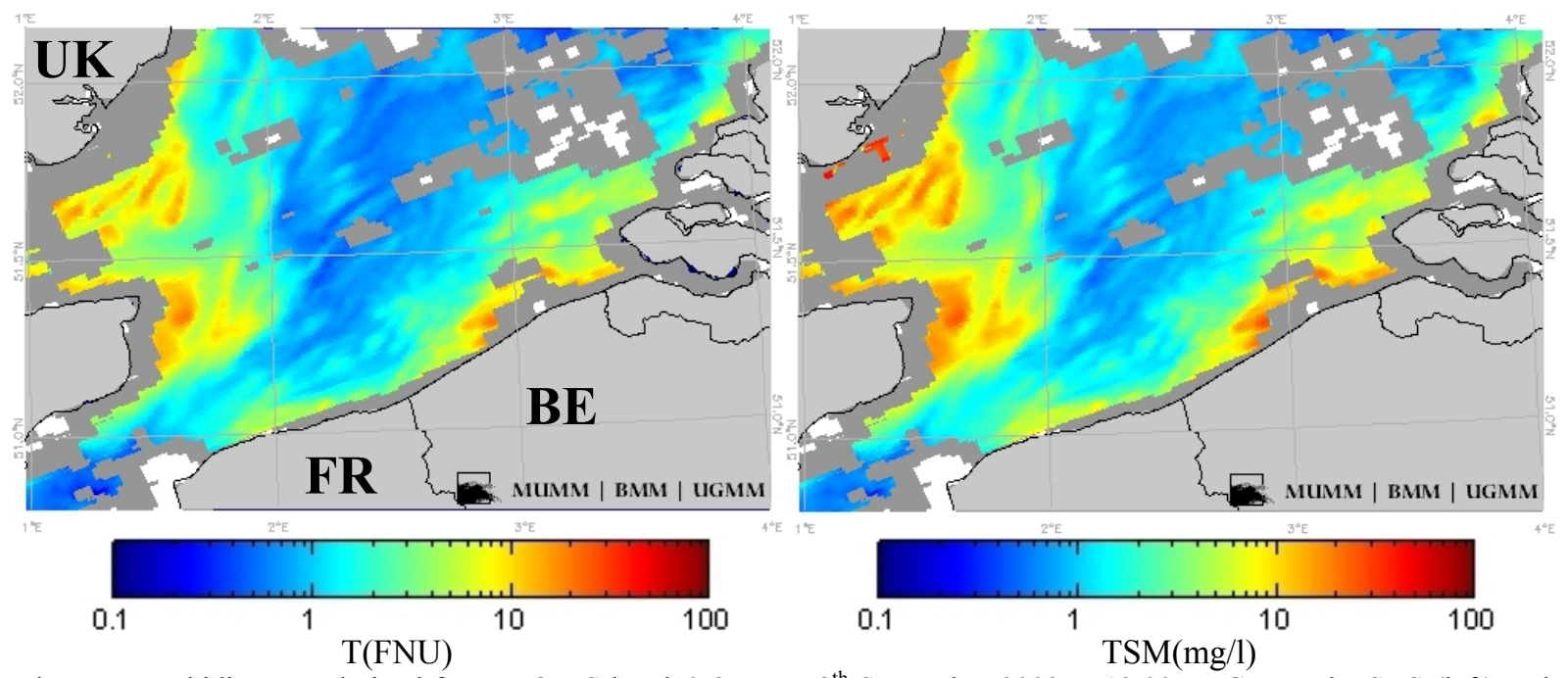

Figure 5: Turbidity map derived from MODIS band $678 \mathrm{~nm}$ on $8^{\text {th }}$ September 2003 at 12:00 UTC over the SNS (left) and TSM concentration map from MODIS band 667nm (right). 


\section{CONCLUSION}

A generic algorithm for turbidity mapping has been calibrated for coastal waters using a bio-optical model and seaborne measurements of turbidity and reflectances. The calibrated parameter $A_{T}$ was tabulated here and may be used to produce turbidity maps from the red or NIR bands of any ocean colour sensor (provided narrow bands are available).

The algorithm calibrated for MERIS bands gives $A_{T}$ at $620 \mathrm{~nm}$ within close agreement with ${ }^{11}$ and shows also the best curve fit between turbidity and reflectance at $681 \mathrm{~nm}$, although different water types were considered and a different approach (empirical method) was used in ${ }^{11}$.

The hyperspectrally calibrated parameter $A_{T}$ reproduced the signature of the pure water absorption, which is explained by the negligible effect of CDOM absorption in the red and NIR spectral range in the studied area, and by the spectrally flat $b_{b p T}^{*}$. This same feature was noticed in the $A_{T S M}$ parameter calibrated using an independent reflectance and TSM dataset in ${ }^{10}$.

The linear relationship between turbidity and TSM in SNS waters is visible in Figure 1a, and exhibits a correlation factor of $98.56 \%$ (for the calibration and validation datasets). This is also underlined by the correlation factor between these $A_{T}$ and $A_{T S M}$, up to $99.97 \%$. The ratio $A_{T} / A_{T S M}$ varies slightly between 0.7 and $0.8 \mathrm{FNU} . \mathrm{m}^{3} / \mathrm{g}$ in the red to NIR spectral range, with an average value of $0.74 \mathrm{FNU} . \mathrm{m}^{3} / \mathrm{g}$. Combining this value with $b_{b p}^{*} \approx 6.8310^{-3} \mathrm{~m}^{2} \mathrm{~g}^{-1}$ estimated at $667 \mathrm{~nm}$ by ${ }^{10}$ provides an estimation of the turbidity-specific backscatter $b_{b p T}^{*}=b_{b p}^{*} /\left(A_{T} / A_{T S M}\right) \approx 9.2310^{-3} \mathrm{~m}^{-1} \mathrm{FNU}^{-1}$.

At present, only a limited number of in situ turbidity and reflectance measurements are available for validation (23), but seaborne measurements are collected on a regular basis in the SNS and in coastal waters elsewhere. These will be complemented with satellite matchups (adding sensor and product-related errors in turbidity retrieval, i.e atmospheric correction uncertainties). Also, this version of the calibrated model gives turbidity in terms of water-leaving reflectance calibrated for a single viewing geometry, but does not take into account possible bidirectional effects. Future work is needed to cover this aspect.

This single band algorithm is easy to implement and as is, represents a simple tool to efficiently meet the recommendations of the Marine Strategy Directive regarding the need for turbidity monitoring.

\section{ACKNOWLEDGEMENTS}

This study was funded by the STEREO programme of the Belgian Federal Science Policy Office in the framework of the BELCOLOUR-2 (SR/00/104) project. MUMM's Chemistry lab is thanked for analysing and providing in situ TSM data. Barbara Van Mol, Geneviève Lacroix and the captain and crew of the Research Vessel Belgica are thanked for their assistance with seaborne measurements. The NASA Ocean Color Product Distribution and SeaDAS teams at GSFC are acknowledged for distributing MODIS products and the SeaDAS software. Vittorio Brando and Emmanuel Boss are thanked for discussions on turbidity and the need for referencing to inherent optical properties.

\section{REFERENCES}


1. European Union. "Marine Strategy Framework Directive 2008/56/EC establihshing a framework for community action in the field of marine environmental policy," Official Journal L164(25/06/2008), 19-40. (2008).

2. Davies-Colley, R. J. and Smith, D.G. "Turbidity, suspended sediment, and water clarity: a review," Journal of the American Water Resources Association 37(5), 1085-1101 (2001).

3. Downing, J. "Turbidity Monitoring," John Wiley \& Sons Inc, Port Townsend Washington (2005).

4. $\quad$ ISO, I. S. O. (1999). "Water quality - determination of turbidity," (1999)

5. $\quad$ EPA, U. S. E. P. A. "Method 180.1 - Determination of turbidity by nephelometry (revision 2.0)," Cincinnati:10 (1993)

6. Barter, P. J. and Deas, T. "Comparison of portable nephelometric turbidimeters on natural waters and effluents," New Zealand Journal of Marine and Freshwater Research 37, 485-492. (2003)

7. Boss, E., Taylor, L., Gilbert, S., Gundersen, K., Hawley, N., Janzen, C., Johengen, T., Purcell, H., Robertson, C., Schar, D. W., Smith G. J. and Tamburri, M. N. "Comparison of inherent optical properties as a surrogate for particulate matter concentration in coastal waters," Limnology and Oceanography (Methods), submitted (2009).

8. Sadar, M. J. “Turbidity science," Hach Company, 26 (1998).

9. Zaneveld, J. R. V. "Optical properties of turbidity standards," Ocean Optics V, SPIE (1979).

10. Nechad, B., Ruddick K. G. and Park, Y. "Calibration and validation of a generic multisensor algorithm for mapping of Total Suspended Matter in turbid waters," Remote Sensing of the Environment, submitted (2009).

11. Ouillon, S., Douillet, P., Petrenko, A., Neveux, J., Dupouy, C., Froidefond, J. M., Andréfouët, S. and MuñozCaravaca, A. "Optical algorithms at satellite wavelenghts for total suspended matter in tropical coastal waters," Sensors 8, 4165-4185 (2008).

12. Bustamente, J., Pacios, F., Diaz-Delgado, R. and Aragonés, D. "Predictive models of turbidity and water depth in the Doñana marshes using LANDSAT TM and ETM+ images," Journal of Environmental Management (2008).

13. Choubey, V. K. "Correlation of turbidity with Indian Remote Sensing Satellite-1A data," Hydrological Sciences 37(2), 129-140 (1992).

14. Goodin, D. G., Harrington, J. A., Druane Nellis, JR, M. and Rundquist, D. C. "Mapping reservoir turbidity patterns using SPOT-HRV data," Geocarto International 11(4), 71-78 (1996).

15. Nechad, B., De Cauwer, V., Park, Y. and Ruddick. K.G. "Suspended Particulate Matter (SPM) mapping from MERIS imagery. Calibration of a regional algorithm for the Belgian coastal waters," In MERIS user workshop, 10-13th November 2003. 2003., Frascati European Space Agency (2003).

16. Gordon, H. R., Brown, O. B. , Evans, R. H. , Brown, J. W., Smith, R. C., Baker, K. S. and Clark, D. K. "A semianalytical radiance model of ocean color," Journal of Geophysical Research 93(D9), 10909-10924 (1988).

17. Morel, A. and Gentili, B. "Diffuse reflectance of oceanic waters. III. Implication of bidirectionality for the remote-sensing problem," Applied Optics 35(24), 4850-4862 (1996).

18. Morel, A. and Gentili B. "Diffuse reflectance of oceanic waters: its dependence on Sun angle as influenced by the molecular scattering contribution," Applied Optics 30(30), 4427-4438 (1991).

19. Loisel, H. and Morel, A. "Non-isotropy of the upward radiance field in typical coastal (Case 2) waters," International Journal of Remote Sensing 22(2 \& 3), 275-295 (2001).

20. Ruddick, K. G., De Cauwer, V., Park, Y. and Moore, G. "Seaborne measurements of near infrared waterleaving reflectance: The similarity spectrum for turbid waters," Limnology and Oceanography (Methods) submitted 51, 1167-1179 (2006).

21. Ruddick, K., Park, Y., Astoreca, R., Neukermans, G. and Van Mol, B. "Validation of MERIS water products in the Southern North Sea: 2002-2008," 2nd MERIS-(A)ASTR workshop (2008).

22. Kleinbaum, D. G., Kupper, L. L. and Muller, K. E. "Regression analysis and other multivariable methods, PWS-KENT Publishing Company," Chapter II, pages 163-227 (1998).

23. Astoreca, R., Ruddick, K. G., Van Mol, B., Rousseau, V., Parent, J.-Y. and Lancelot, C. "Variability of the inherent and apparent optical properties in a highly turbid coastal area: impact for the calibration of remote sensing algorithms," EARSeL eProceedings (2006).

24. Kou, L., Labrie, D. and Chylek, P. "Refractive indices of water and ice in the $0.65-2.5 \mu \mathrm{m}$ spectral range," Applied Optics 32, 3531-3540 (1993).

25. Buiteveld, H., Hakvoort, J. H. M. and Donze, M. "The optical properties of pure water," In the proceedings of Ocean Optics XII. J.S. Jaffe, SPIE. 2258, 174-183 (1994).

26. Ruddick, K. G., Ovidio, F., and Rijkeboer, M. "Atmospheric correction of SeaWiFS imagery for turbid coastal and inland waters," Applied Optics 39 (6), 897-912 (2000). 